\title{
Advances in Materials
}

\section{$\mathrm{ZnO}$ and $\mathrm{ZnO}: \mathrm{Ga}$ Ceramics for Advanced Scintillators}

\author{
Donats Millers $^{1,}$,, Larisa Grigorjeva ${ }^{1}$, Aleksejs Zolotarjovs ${ }^{1}$, Faina Muktepavela ${ }^{1}$, Jurgis Grube ${ }^{1}$, \\ Agnese Spustaka $^{1}$, Piotr Rodnyi ${ }^{2}$, Ivan Venevtsev ${ }^{2}$, Elena Gorokhova ${ }^{3}$ \\ ${ }^{1}$ Institute of Solid State Physics, University of Latvia, Riga, Latvia \\ ${ }^{2}$ Experimental Physics Department, Peter the Great Saint Petersburg Polytechnic University, Saint-Petersburg, Russia \\ ${ }^{3}$ Vavilov State Optical Institute, Saint Petersburg, Russia
}

Email address:

dmillers@latnet.lv (D. Millers)

${ }^{*}$ Corresponding author

\section{To cite this article:}

Donats Millers, Larisa Grigorjeva, Aleksejs Zolotarjovs, Faina Muktepavela, Jurgis Grube, Agnese Spustaka, Piotr Rodnyi, Ivan Venevtsev, Elena Gorokhova. ZnO and ZnO:Ga Ceramics for Advanced Scintillators. Advances in Materials. Vol. 9, No. 4, 2020, pp. 94-101. doi: $10.11648 /$ j.am.20200904.13

Received: November 24, 2020; Accepted: December 8, 2020; Published: December 22, 2020

\begin{abstract}
The undoped $\mathrm{ZnO}$ reveals narrow luminescence bands located close to fundamental absorption edge, known as near band luminescence (NBL) and defects related wide luminescence band within visible range of spectrum. NBL decay is in sub-nanosecond range and it is promising for fast scintillator development. However, the defects luminescence decay is in microsecond range and it is disturbing for fast scintillators. Dopants strongly change the luminescence properties, mainly the intensity and decay time and that is the cause for intense study of doped $\mathrm{ZnO}$ luminescence properties. Thus the study of luminescent properties of undoped $\mathrm{ZnO}$ and doped $\mathrm{ZnO}$ : Ga ceramics was carried out. The dependence of the radioluminescence intensity on temperature and spectrum of near band edge luminescence were examined. NBL spectra comparison of $\mathrm{ZnO}$ and $\mathrm{ZnO}: \mathrm{Ga}$ ceramics with $\mathrm{ZnO}: \mathrm{Ga}$ single crystal allowed drawn out that at $300 \mathrm{~K}$ the donor-acceptor pair luminescence is dominant. It was suggested that the reabsorption within band edge spectral region could significantly affected the near band luminescence intensity and spectral position at $300 \mathrm{~K}$. The significant impact of gallium on the $\mathrm{ZnO}$ luminescence is observed. The decay kinetics of luminescence were studied in picosecond range and the two-stage luminescence decay was found for undoped $\mathrm{ZnO}$. The fastest decay stage time is determined to be within $37-57$ ps. One stage decay kinetics of NBL was determined for $\mathrm{ZnO}: \mathrm{Ga}$ ceramic and decay time of $17 \mathrm{ps}$ was estimated.
\end{abstract}

Keywords: ZnO, ZnO:Ga, Fast Luminescence, Decay kinetics, Radioluminescence, Scintillator

\section{Introduction}

$\mathrm{ZnO}$ is a wide-band semiconductor with band gap energy of $3.37 \mathrm{eV}$ and large exciton binding energy - $60 \mathrm{meV}$. ZnO can be found in a large number of applications - as catalysts, ceramic varistors, cosmetics, solar cell semi-transparent windows, gas sensors, detectors and many other [1-5]. Various applications require quality $\mathrm{ZnO}$ nanoparticles and it depends on synthesis procedure as well as on dopands [6]. The $\mathrm{ZnO}$ has been known also as a promising fast scintillator for over forty years [7]. In addition, high exciton binding energy allows observation of the excitonic related luminescence even at room temperature. The low temperature excitonic luminescence is widely studied and the bands observed were interpreted in detail [8-11].
The near band luminescence (NBL) at $300 \mathrm{~K}$ is studied extensively in $\mathrm{ZnO}$ single crystals, films and lately in ceramics, including semi-transparent ceramics [12-16]. It was found that the powdered zinc oxide doped with gallium possesses a short de-excitation time of $0.7 \mathrm{~ns}$ and a high luminous yield up to 15 000 photons $/ \mathrm{MeV}$ [17]. However, the use of powders as scintillators meet technical problems, therefore the study of $\mathrm{ZnO}$ single crystals as well as ceramics is of importance. The $\mathrm{ZnO}$ single crystal is good material for fast scintillator pulses detection - it reveals rise-times of less than $100 \mathrm{ps}$, and fall times below $1 \mathrm{~ns}$; however, the growth of the qualitative single crystal is not easy [18]. The study of fast scintillators required advanced technics application since the rise time and decay time of scintillation pulses are very short. To record such short decay times of luminescence various equipment is used and 
frequently the determined decay times are affected by response time of the system used, including the excitation pulse time characteristics. This is one of the possible reasons for the large variation in the published results of the $\mathrm{ZnO}$ exciton related luminescence decay time. Also, very important factors affecting the temporal characteristics are the morphology of the samples (powder, film, ceramic and etc.), post-synthesis thermal treatment of samples, the impurity and host defects content in composition.

The most popular dopants are $\mathrm{Ga}$, In, or $\mathrm{Al}$, all them act as donors; the incorporation of these dopants affects the intensity of excitonic luminescence and electric conductivity, especially if the concentration of donor centers increases [1, 19]. The important and still unanswered is the question how the impurity ions are embedded in nanocrystals and ceramics grains and its boundaries. The distribution of dopants in nanopowders and ceramics is the subject of many studies.

Despite of many studies, details of scintillation mechanism at $300 \mathrm{~K}$ remains unknown. The NBL at $3.18 \mathrm{eV}$ showed the fast decay, previously characterized in $\mathrm{ZnO}$ as well as in $\mathrm{ZnO}: \mathrm{Ga}$ single crystal samples [20, 21]. The proposed mechanism includes DAP recombination and indicates the presence of both - donor centers and acceptor centers also. The DAP decay is not simply exponential and decay down to $50 \%$ from initial intensity occur within $5,5 \mathrm{~ns}$ in undoped and nitrogen doped single crystals at $16 \mathrm{~K}$ [22]. Efficient ultrafast scintillations have been observed in $\mathrm{ZnO}: \mathrm{Ga}$ and $\mathrm{ZnO}: \mathrm{In}$ compositions [18, 23]. It is known that the unexpected impurities as well as doping greatly affect the scintillation response time. It was demonstrated that in undoped $\mathrm{ZnO}$ single crystals the luminescence decay time varies between $130 \mathrm{ps}$ and $1.7 \mathrm{~ns}$, whereas in $\mathrm{ZnO}$ :In single crystal the response time of 15 ps was achieved [24].

The NBL intensity fast decay over four orders of magnitude, that could be estimated and it indicate the doped $\mathrm{ZnO}$ ceramics are promising for scintillators [10, 25]. It is known that in ceramics the fundamental absorption edge is usually shifted to the low-energy side of the spectrum. This is due to the structural disorder or disorder related to dopants. The position of fundamental absorption edge is affected by morphology and particle size. The luminescence decay curves for hot pressed ceramics $\mathrm{ZnO}$ doped with $\mathrm{Ga}$ were recorded under pulsed X-ray excitation using the time-correlated photon counting detection system $[26,27]$. The estimated decay time obtained for NBL band was 0.7 ns. It is a good result, since $\mathrm{ZnO}$ ceramic is of interest for its use as the scintillation detector. However, it is necessary to improve the structural, mechanical and luminescent properties of $\mathrm{ZnO}$ ceramics, bringing them to perfection.

The present research is motivated by the need for better understanding of the scintillations nature in $\mathrm{ZnO}$ and $\mathrm{ZnO}: \mathrm{Ga}$ ceramics sintered by uniaxial hot pressing, as well as estimate luminescence decay time. Therefore the NBL of ceramics is studied and for comparison the $\mathrm{ZnO}$ :Ga single crystal is used. The defect luminescence in green/yellow spectral region was not studied in this paper. The time-resolved luminescence studies under picosecond excitation were used for the study of luminescence decay process.

\section{Experimental}

The ceramic samples were made from powders obtained by hydrothermal method followed by annealing at $850^{\circ} \mathrm{C}$ in air. The sintering of ceramics was conducted by uniaxial hot pressing of powder in vacuum at $1100^{\circ} \mathrm{C}$ under pressure 150 $\mathrm{MPa}$. The ceramics samples for experiments were disks with $24 \mathrm{~mm}$ diameter and $\sim 0.5 \mathrm{~mm}$ thickness. The sintering technology was described in detail in [27]. The undoped $\mathrm{ZnO}$ ceramics and doped $\mathrm{ZnO}: \mathrm{Ga}(0.1$ wt.\% Ga) ceramics were used in the present study. The $\mathrm{ZnO}$ :Ga single crystal was used for luminescence spectra comparison.

Microstructure and fracture mode of ceramics were studied by optical (Nicon Eclipse 120) microscope and scanning electron (SEM, Phenom Pro) microscope. The crystallinity of ceramics was determined by XRD using a Rigaku MiniFlex $600 \mathrm{X}$-ray diffractometer. $\mathrm{Cu} \mathrm{K} \alpha$ radiation was used by setting the cathode voltage to $40 \mathrm{kV}$ and current to $15 \mathrm{~mA}$.

Photoluminescence was excited using $266 \mathrm{~nm}$ wavelength-tuneable picosecond solid state laser, FWHM of pulse is $24 \mathrm{ps}$, fall time 17 ps between intensity levels $0.9-0.1$, pulse energy of around $160 \mu \mathrm{J} / \mathrm{cm}^{2}$. The laser beam was focused on the sample using convex lens. Laser beam spot size was around $6 \mathrm{~mm}^{2}$. Bruker 250IS/SM spectrograph with grating $150 \mathrm{l} / \mathrm{mm}$ at blaze $300 \mathrm{~nm}$ was used for spectral region selection. The spectra excited with laser pulses were measured within time range $0 \div 1 \mathrm{~ns}$ (where $0 \mathrm{~ns}$ is laser pulse start time).

The time integrated radioluminescence spectra were measured under x-ray excitation. X-ray tube with tungsten anode was operated at $30 \mathrm{kV}$ and $10 \mathrm{~mA}$. The spectra of luminescence were recorded using Andor Shamrock B-303i spectrograph equipped with Andor DV-401A-BV CCD camera.

\section{Results and Discussion}

\subsection{Crystalline Structure}

The $\mathrm{ZnO}$ :Ga ceramics XRD pattern was recorded at RT for $2 \theta$ within $10-70$ degrees. Obtained XRD data matches well with those of card JCPDS 036-1451 (Figure 1) indicating that ceramics grains have hexagonal wurtzite structure.

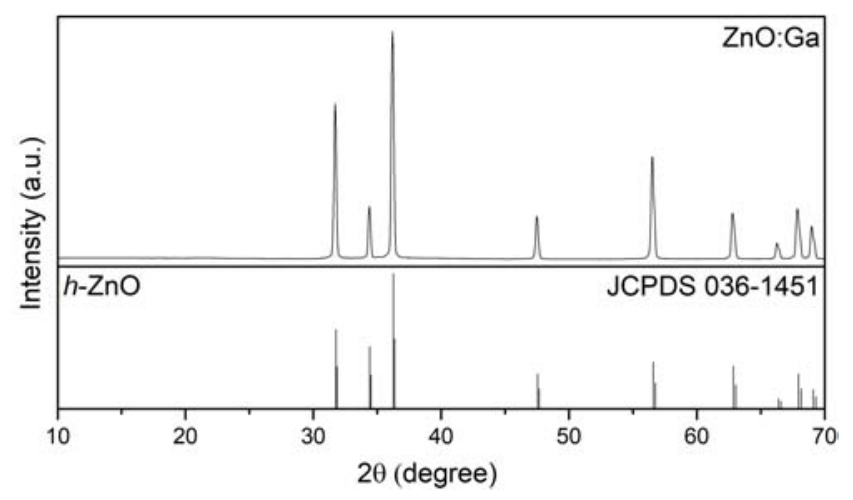

Figure 1. XRD pattern of $\mathrm{ZnO}$ :Ga ceramics. 
The other phases were not detected and it confirms the Ga substitutes for $\mathrm{Zn}$ in $\mathrm{ZnO}$ wurtzite structure. Therefore in $\mathrm{ZnO}: \mathrm{Ga}$ ceramics the additional donor levels were introduced [28]. Undoped $\mathrm{ZnO}$ ceramics have wurtzite structure also.

\subsection{Microstructure of Ceramics}

The microstructure of both undoped and doped ceramics is very heterogeneous in grain size: $d_{g}=5-25 \mu \mathrm{m}$ in $\mathrm{ZnO}$ ceramic and $\mathrm{d}_{\mathrm{g}}=2,5-22 \mu \mathrm{m}$ in $\mathrm{ZnO}$ : Ga ceramic (Figure 2a, b). In $\mathrm{Ga}$ doped $\mathrm{ZnO}$ ceramics the grains are a little smaller than those in undoped $\mathrm{ZnO}$ ceramic. Moreover, there is a tendency to change the shape of some grains. True, not to the same extent, as under the influence of indium, however, this process is noticeable and according to known mechanisms of the sintering process, can be associated with the gallium influence on the grain growth stage $[15,29,30]$. The effect of gallium on the ceramics structure formation is confirmed by the SEM images of fracture mode results (Figure $2 c, d$ ).

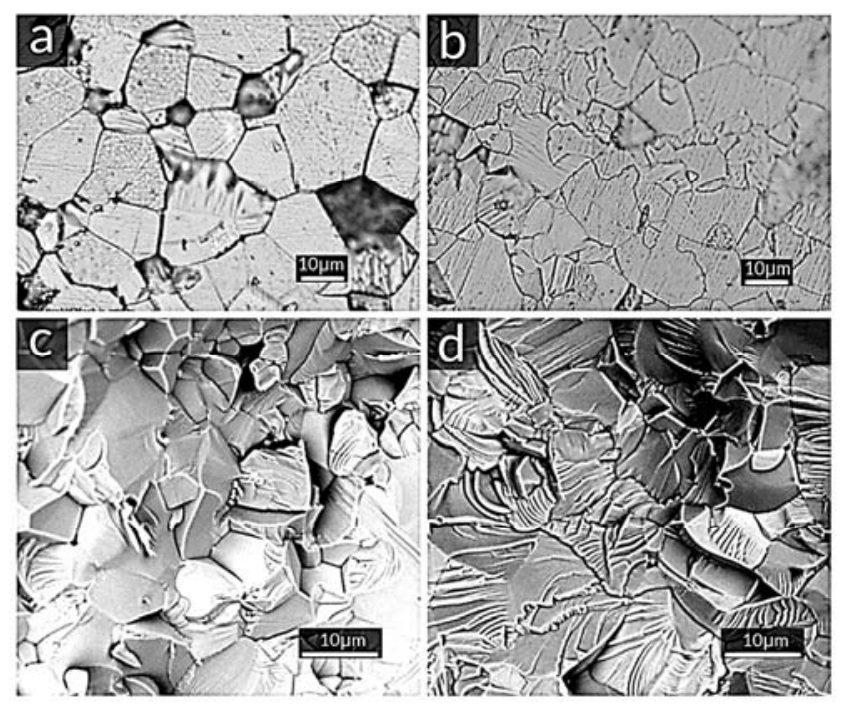

Figure 2. Micrographs of etched surfaces ( $a, b)$, and SEM images of fracture surfaces $(c, d)$ of undoped $(a, c)$ and $G a$ doped $(b, d)$ ceramics.

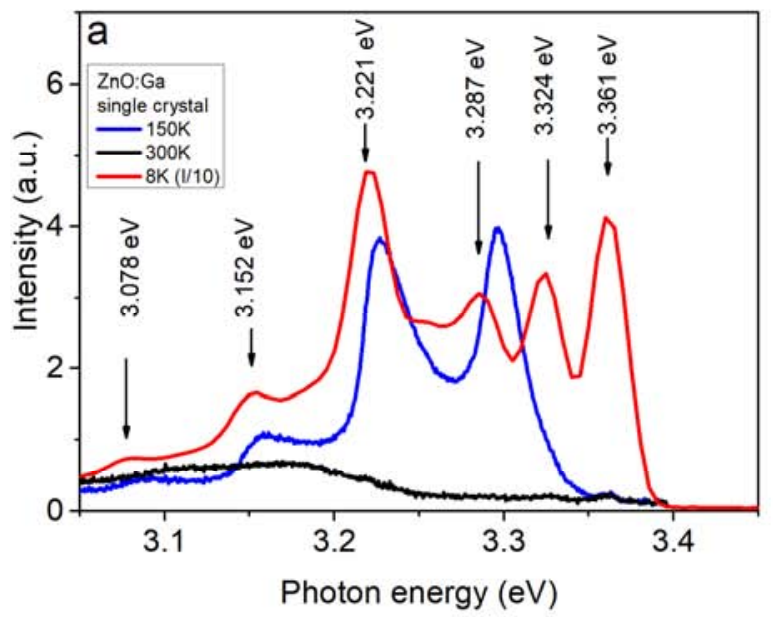

As one can see, undoped $\mathrm{ZnO}$ ceramic sample has mainly intergranular fracture mode (Figure 2, c). At the same time, gallium-doped ceramic sample is characterized by predominant brittle transcrystalline fracture (Figure 2, d) with many steps of cleavage inside the grains. Appearance of these fractures elements is due gallium-induced change the nature of the cracks propagation, which in turn indicates a new structural state of ceramics. As shown by Vorobyeva N. et al, the formation of compounds or $\mathrm{ZnO}+\mathrm{Ga}_{2} \mathrm{O}_{3}$ solid solution is possible when doping $\mathrm{ZnO}$ with $\mathrm{Ga}_{2} \mathrm{O}_{3}$, leading to the increased manifestation of the donor properties of gallium, however XRD showed only the wurzite phase of ceramic samples used in the present study [31].

Micropores and voids are also visible in the microstructures of both undoped and gallium doped samples, which for $\mathrm{ZnO}$ ceramics is a characteristic consequence of powder agglomeration processes, reinforced in this case by preliminary annealing of powders at $850^{\circ} \mathrm{C}$ [29].

The presence of these defects determined the semi-transparency of ceramics obtained for this study: for undoped $\mathrm{ZnO}$ ceramic the transparency is $\sim 15 \%$ at $500 \mathrm{~nm}$, at the same time, others $\mathrm{ZnO}$ samples where powders agglomeration was not so intense showed transparency close to $60 \%$ at $500 \mathrm{~nm}[15]$.

The influence of morphology and grain size of ceramics properties is significant and it is known that the fundamental absorption edge of ceramics is shifted to the low-energy side of the spectrum due to the ceramics structural disorder and disorder related to dopants $[15,16]$.

\subsection{Luminescence}

\subsubsection{Radioluminescence}

The radioluminescence shows all luminescence processes under band-to-band excitation. The radioluminescence spectra of $\mathrm{ZnO}: \mathrm{Ga}$ single crystal and ceramics were recorded under continuous X-ray excitation at different temperatures. The NBL was observed for both materials, however the spectra differ significantly (Figure 3).

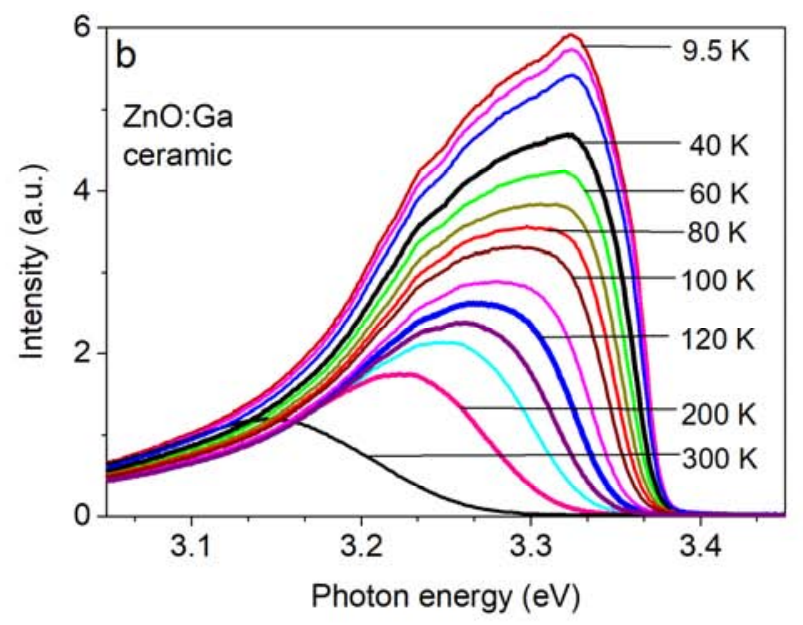

Figure 3. Radioluminscence spectra of $\mathrm{ZnO}: \mathrm{Ga}$ single crystal (a) and $\mathrm{ZnO}$ :Ga ceramics at different temperatures (b). 
described in $[1,10]$. The position of $\operatorname{ExD}^{0}$ luminescence peak at $8 \mathrm{~K}$ in high quality $\mathrm{ZnO}$ single crystal is at $3.3605 \mathrm{eV}$ [1]. In $\mathrm{ZnO}: \mathrm{Ga}$ single crystal this peak position is at $3.361 \mathrm{eV}$ (Figure $3 a)$ and it is close to position in undoped crystal. The positions of other peaks are close to those observed in undoped crystal also. Therefore, the interpretation of luminescence bands is the same as found by Ozgur, U. et al and Meyer, B. K. et al and corresponding bands positions, its origin and marks are in the Table $1,[1,10]$. The longitudinal optical phonon (LO) energy is $0.072 \mathrm{eV}$ in $\mathrm{ZnO}$ and even in nanocrystals LO phonon energy is the same $[32,33]$. Therefore, the LO phonon replicas positions of corresponding luminescence bands were estimated from the spectrum in Figure 3a.

Table 1. Luminescence bands of ZnO:Ga single crystal at $8 \mathrm{~K}$.

\begin{tabular}{lll}
\hline Band position, $\mathbf{e V}$ & Origin of band & Marks used in the text \\
\hline 3.361 & Exciton bound at neutral donor & ExD $^{0}$ \\
3.324 & Two-electron satellite of exciton bound at neutral donor & $\mathrm{TES} \mathrm{ExD}^{0}$ \\
3.287 & 1LO phonon replica of the exciton bound at neutral donor & 1LO-ExD \\
3.221 & Donor-Acceptor-Pair transition & DAP \\
3.152 & 1LO phonon replica of the Donor-Acceptor-Pair transition & 1LO-DAP \\
3.078 & 2LO phonon replica of the Donor-Acceptor-Pair transition & 2 LO-DAP \\
\hline
\end{tabular}

One could note that the position of luminescence band peaking at $3.221 \mathrm{eV}$ is close to the position of possible $2 \mathrm{LO}$ phonon replica for $\mathrm{ExD}^{\circ}$ band since $3.361-2 \times 0.072=3.217$. There is a small disagreement in energy of band position, and it could arise due to accuracy of band position determination. The most important is that intensity of the band peaking at $3.221 \mathrm{eV}$ significantly exceed that for $1 \mathrm{LO}-\mathrm{ExD}^{\circ}$ band. The intensity of two phonon replica must be less than that for one phonon replica, therefore the band peaking at $3.221 \mathrm{eV}$ cannot be $2 \mathrm{LO}-\mathrm{ExD}^{\circ}$ replica. The position of band at $3.221 \mathrm{eV}$ matches well with that for donor-acceptor pair transition (DAP) [10].

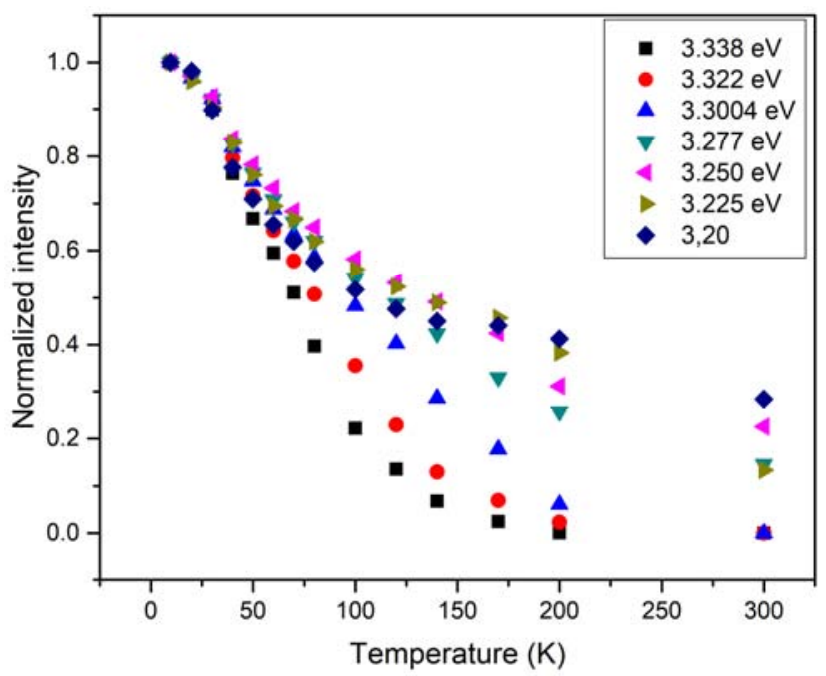

Figure 4. ZnO:Ga ceramics luminescence intensity dependence on temperature.

The $\mathrm{ZnO}$ :Ga ceramics showed a wide asymmetric NBL band in a wide temperature range from $9.5 \mathrm{~K}$ up to $300 \mathrm{~K}$, Figure $3 \mathrm{~b}$. This luminescence band covers the same spectral range as the NBL of $\mathrm{ZnO}: \mathrm{Ga}$ single crystal, Figure $3 \mathrm{a}, \mathrm{b}$. However, the separate narrow bands were not resolved in $\mathrm{ZnO}: \mathrm{Ga}$ ceramics spectra and high energy side of the band could be hidden under fundamental absorption edge. At $9.5 \mathrm{~K}$ the $\mathrm{ZnO}: \mathrm{Ga}$ ceramics luminescence is cut of at $\sim 3.38 \mathrm{eV}$ (Figure $3 b$ ), whereas in single crystal luminescence at this wavelength the tail of $\mathrm{ExD}^{\circ}$ band is recorded. The $\mathrm{ZnO}: \mathrm{Ga}$ ceramics luminescence intensity dependence on temperature for a number of photon energies is shown in Figure 4. Since intensities of luminescence covers the wide range within whole band, the normalized intensity is used. These dependencies differ suggesting that the temperature quenching of luminescence (thermal activation energies) differs also and luminescence within $3.300-3.338 \mathrm{eV}$ shows the strongest thermal quenching.

The asymmetric shape of the $\mathrm{ZnO}: \mathrm{Ga}$ ceramics luminescence band as well as luminescence intensity and the band shape dependences on temperature are the strong evidences that several bands overlaps. The overlapping luminescence bands are greatly affected by disorder of ceramics structure (positions, FWHM). In this case responsible for luminescence band components could be luminescence due to excitonic processes as well as to slightly different donor-acceptor pairs and electrons recombination with acceptors.

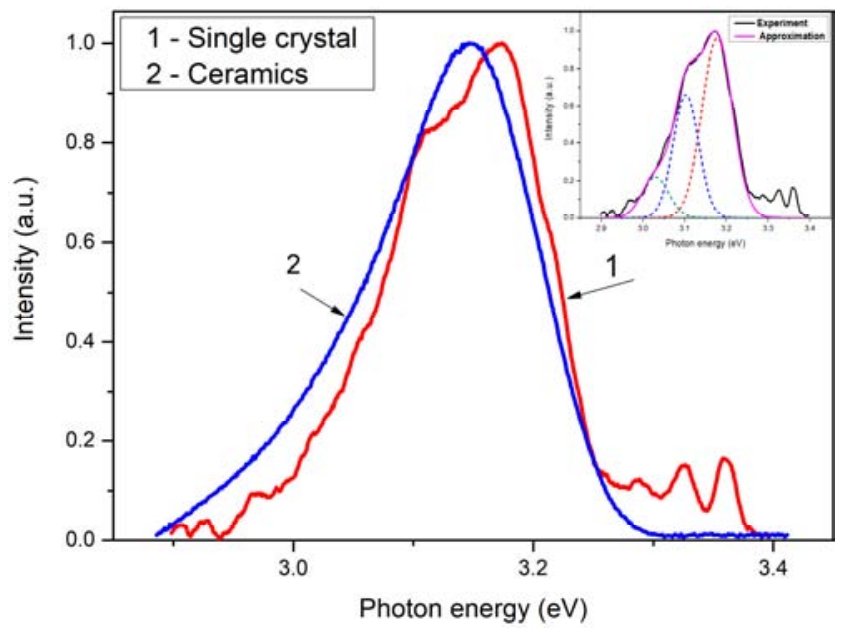

Figure 5. ZnO:Ga radioluminescence spectra at $300 \mathrm{~K}$, a single crystal - 1, ceramics - 2; inset - approximation of single crystal luminescence spectrum by 3 Gaussians.

The similar asymmetric luminescence band was observed by K. A. Chernenko et al. [15]. The possible contributions 
from bound excitons recombination and others $\left(\mathrm{ExD}^{0}, \mathrm{ExD}^{+}\right.$, at lattice defects, DAP, etc.) could be suggested. The attempts to decompose NBL band was carried out by D. Das and P. Mondal and the best fit to experiment was reached by using 5 or 6 Gaussians for approximation [34, 35]. However, the possible overlapping of luminescence band with fundamental absorption edge there was not taken into account. Hence there is not a strong ground that this set of Gaussians is only possible version for experimental spectrum approximation. One could note a large number of variables - each Gaussian have 3 variables (position, amplitude and FWHM), hence up to 15 or 18 variables can be used for deconvolution of experimental curve and therefore the interpretation of components found could be ambiguous.

The room temperature luminescence is most important for scintillators. The $\mathrm{ZnO}: \mathrm{Ga}$ single crystal and ceramics radioluminescence spectra at $300 \mathrm{~K}$ both covers the same spectral range peaking within $3.12-3.19 \mathrm{eV}$ (Figure 5), however the spectra were not the same. The spectrum of single crystals reveals well resolved bands of $\mathrm{ExD}^{\circ}, \mathrm{TES} \mathrm{ExD}^{\circ}$ and $1 \mathrm{LO}-\mathrm{ExD}^{\circ}$ luminescence within $3.25-3.40 \mathrm{eV}$ range. The intensities of these bands were reduced due to thermal quenching. The more intense luminescence band of $\mathrm{ZnO}: \mathrm{Ga}$ single crystal is peaking at $3.18 \mathrm{eV}$ and has a shoulder within $3.094-3.136 \mathrm{eV}$, thus the band is complex. This luminescence band can be approximated with a sum of three Gaussians (inset of Figure 5) peaking at 3.032, 3.104 and $3.178 \mathrm{eV}$. These positions are close to the DAP bands recorded at $8 \mathrm{~K}$ (Figure 3a, Table 1.), however the positions were slightly shifted to long wave side. The dominant DAP luminescence was observed for $\mathrm{ZnO}$ : Ga thin films at room temperature [36]. Therefore, it is suggested the $\mathrm{ZnO}: \mathrm{Ga}$ ceramics NBL at room temperature is from donor-acceptor-pairs transitions also.

The $\mathrm{ZnO}$ :Ga ceramics radioluminescence spectrum at 300 $\mathrm{K}$ contains one structureless band peaking at $3.147 \mathrm{eV}$. There was not any luminescence band above $3.3 \mathrm{eV}$, possibly this range is covered by a strong fundamental absorption. The disorder in ceramics is a reason for luminescence bands widening and shifting, thus the shoulder of band, similar to that observed for single crystal, is not revealed, however luminescence band is asymmetric. Therefore the main contribution in $\mathrm{ZnO}: \mathrm{Ga}$ single crystal and ceramics radioluminescence at $300 \mathrm{~K}$ is from donor-acceptor-pairs transitions.

\subsubsection{Photoluminescence Under Picosecond Excitation}

Figure 6 (a) and (b) shows the streak camera images of photoluminescence at $\mathrm{RT}$ for undoped $\mathrm{ZnO}$ ceramic and doped $\mathrm{ZnO}: \mathrm{Ga}$ respectively. The faster decay process was observed for $\mathrm{ZnO}$ : Ga ceramic (Figure $6 \mathrm{~b}$ ).

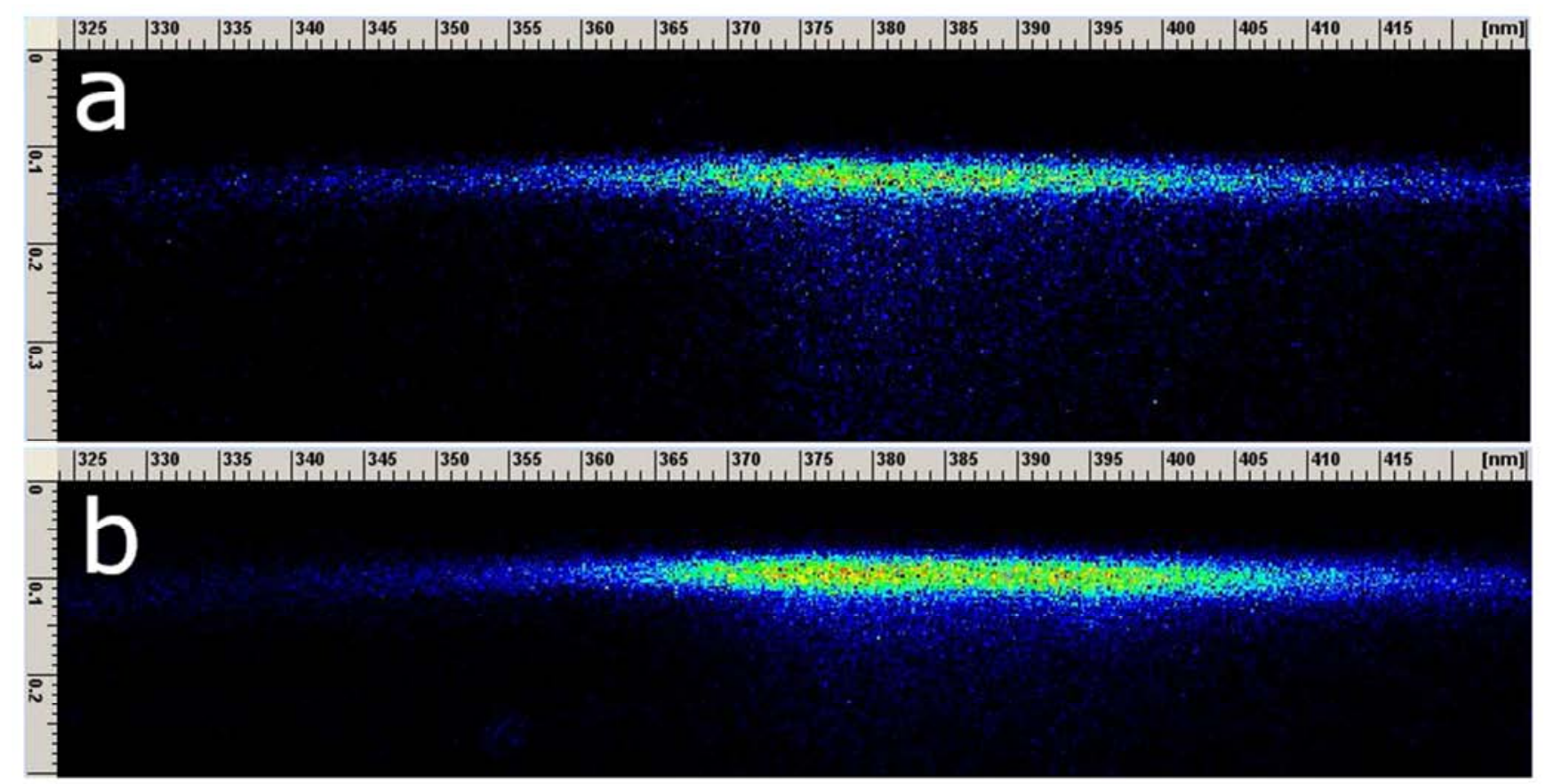

Figure 6. Streak camera images of $\mathrm{ZnO}$ undoped ceramic (a) and $\mathrm{ZnO}$ : Ga ceramic (b) in NBL spectral region. In (a) the time range is 0-0.4 ns and in (b) the time range is 0-0.3 ns. (wavelength axis in $\mathrm{nm}$ horizontal, time axis in $n s$ vertical).

The luminescence spectra at room temperature under picosecond excitation in NBL spectral region are shown for three samples in Figure 7. The luminescence spectra for single crystal and for both ceramics contained a complex band. A detailed analysis of the spectra showed that at least two (possibly more) bands overlapped in each spectrum. The single crystal photoluminescence spectrum matches well with that of radioluminescence at $300 \mathrm{~K}$ (Figure 5.), the shoulder at $3.1 \mathrm{eV}$ is an evidence of luminescence bands overlapping. The spectrum of $\mathrm{ZnO}: \mathrm{Ga}$ ceramics differs from that of radioluminescence - two overlapping bands can be resolved peaking at $\sim 3.14 \mathrm{eV}$ and $\sim 3.28 \mathrm{eV}$. The peak position at 3.14 $\mathrm{eV}$ is the same as in radioluminescence spectrum, whereas at $300 \mathrm{~K}$ there was not resolved as possible separate 
radioluminescence band at $3.28 \mathrm{eV}$. It is noted that peak position at $3.28 \mathrm{eV}$ is close to the $\mathrm{ExD}^{\circ}$ band position in $\mathrm{ZnO}$ :Ga single crystal at $8 \mathrm{~K}$. The peak position shifts to the longer wavelength could be due to higher temperature as well as due to disorder in $\mathrm{ZnO}$ : Ga ceramics structure. The absence of this peak in radioluminescence spectrum is related to the shorter life time of $\mathrm{ExD}^{\circ}$ complex. Thus, we assume in $\mathrm{ZnO}: \mathrm{Ga}$ ceramics the $\mathrm{ExD}^{\circ}$ is responsible for luminescence band peaking at $\sim 3,28 \mathrm{eV}$.

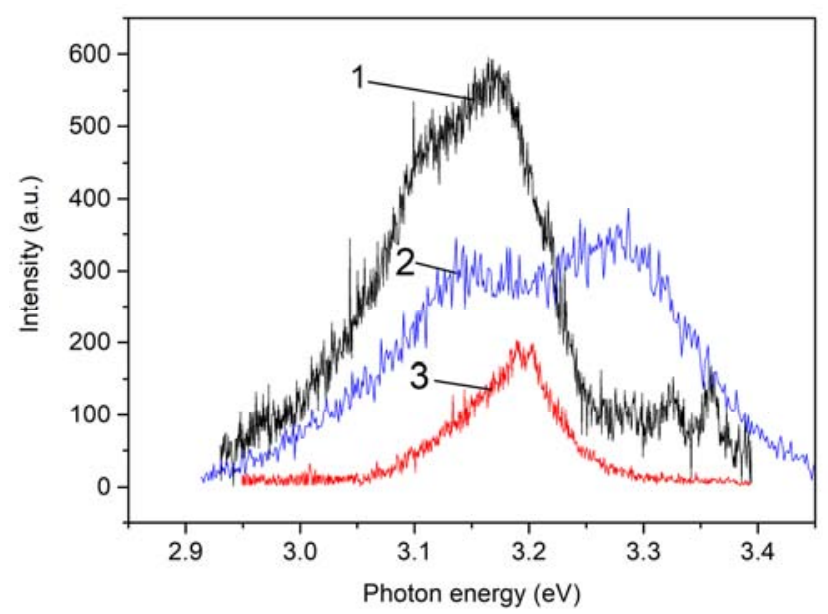

Figure 7. Time-integrated (1 ns) photoluminescence spectra: $1-\mathrm{ZnO}: \mathrm{Ga}$ single crystal, 2 - ZnO:Ga ceramic, 3 - ZnO undoped ceramic at 300K, 266 nm excitation.

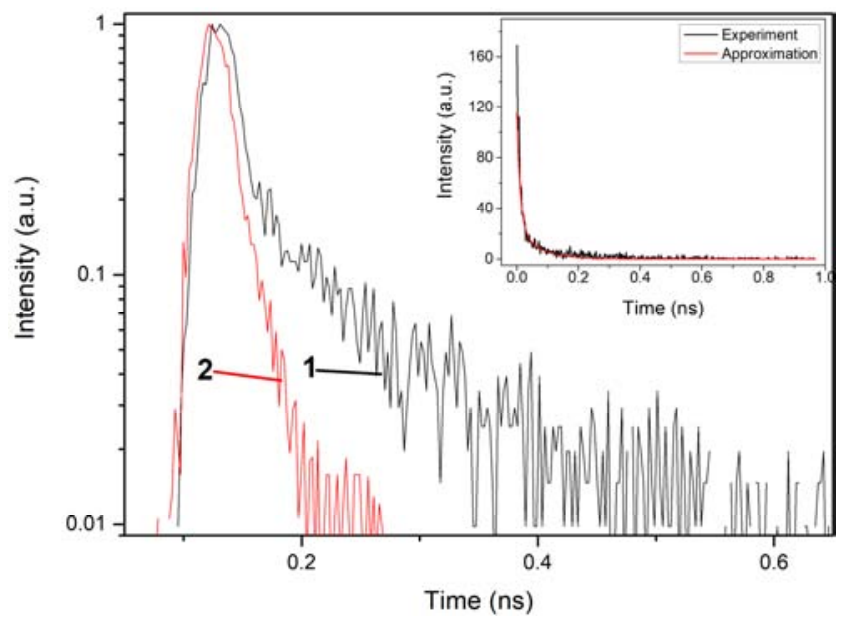

Figure 8. The luminescence kinetics of ceramics: 1- undoped $\mathrm{ZnO}$, 2$\mathrm{ZnO}: \mathrm{Ga}$. Inset - undoped $\mathrm{ZnO}$ luminescence decay at $3.29 \mathrm{eV}$ approximation with 2 exponents.

\subsubsection{Luminescence Decay Kinetics in 1 ns Time Scale}

The analysis of decay kinetics was performed in models of single and two exponential functions. Two exponential decay process is observed in $\mathrm{ZnO}$ single crystal for both luminescence bands [20]. The fitting allows estimation of decay times and to determine is there one or several processes involved. In Figure 8 the luminescence kinetics measured at $3.29 \mathrm{eV}$ for undoped $\mathrm{ZnO}$ and doped $\mathrm{ZnO}: \mathrm{Ga}$ ceramics are shown. The slowest decay of luminescence is for undoped $\mathrm{ZnO}$ ceramics. Therefore, doping with $\mathrm{Ga}$ resulted in significantly shorter decay kinetic thus making the material more prospective for fast operating scintillators. A similar effect was observed in $\mathrm{ZnO}: \mathrm{In}$ ceramic [25].

The two-exponent decay of luminescence was observed in range $3.10-3.25 \mathrm{eV}$ in $\mathrm{ZnO}: \mathrm{Ga}$ single crystal and undoped $\mathrm{ZnO}$ ceramic. The undoped $\mathrm{ZnO}$ ceramics luminescence decay approximation with 2 exponents is shown in the inset in Figure 8. In this case there is a fast component with decay times within $37-57$ ps and slow component with decay times in range 65-115 ps. The origin of two components of decay kinetics is slightly different donor - acceptor pairs, possibly due to diverse nearest surrounding of pairs. Therefore, the overlapping luminescence bands contributed in spectrum (Figure 5, inset). In $\mathrm{ZnO}: \mathrm{Ga}$ ceramic in 3.29-3.33 eV region only one decay component is detected with decay time constant $17 \mathrm{ps}$, whereas at $3.1 \mathrm{eV}$ the fast decay time constant $19 \mathrm{ps}$ is estimated and additionally slower decay with time constant 97 ps appear. However, the intensity of this component does not exceed $\sim 7 \%$ of total luminescence intensity. The value of $\mathrm{ZnO}$ : Ga ceramics NBL decay time $17 \mathrm{ps}$ is close to that (15 ps) found for $\mathrm{ZnO}: \mathrm{In}$, therefore both compositions are promising for advanced scintillators [24]. The analysis of $\mathrm{ZnO}$ :Ga ceramics NBL decay suggest that in short wave range contribution from $\mathrm{ExD}^{\circ}$ luminescence is and possible donor could be Gallium, since in undoped $\mathrm{ZnO}$ ceramics NBL spectrum was not observed band peaking at $\sim 3.28 \mathrm{eV}$. Deconvolution procedure was not performed for luminescence decay analysis and $17 \mathrm{ps}$ is the time resolution limit of equipment used. This limit is determined by laser pulse. Therefore, it cannot be excluded that really $\mathrm{ZnO}: \mathrm{Ga}$ ceramics luminescence decay could be faster.

\section{Summary}

The NBL in $\mathrm{ZnO}$ :Ga single crystal and $\mathrm{ZnO}$ :Ga ceramics covered the same spectral region. It is shown that the NBL at $300 \mathrm{~K}$ is due to the luminescence of the DAP, additionally at $3.28 \mathrm{eV}$ the $\mathrm{ExD}^{\circ}$ is suggested. The luminescence spectrum of $\mathrm{ZnO}$ : Ga single crystal at $300 \mathrm{~K}$ can be well approximated with 3 overlapping Gaussians (at $\sim 3.032 \mathrm{eV}, 3.104 \mathrm{eV}$ and $\sim 3.178 \mathrm{eV}$ ) exhibiting sub-nanosecond decay times. The morphology of samples gave an evidence that $\mathrm{ZnO}: \mathrm{Ga}$ ceramics is more disordered than undoped $\mathrm{ZnO}$ ceramics. The doping of $\mathrm{ZnO}$ with $\mathrm{Ga}$ shortens the decay time considerably and it was estimated to be within $17-19$ ps, while undoped $\mathrm{ZnO}$ ceramic sample shows $37-57$ ps decay time for faster component (depending on the spectral position of the scintillation).

Further development of the technology for manufacturing of transparent $\mathrm{ZnO}$ and $\mathrm{ZnO}: \mathrm{Ga}$ ceramics (by using the uniform initial powder, increasing the transparency and homogeneity of ceramics) will provide an opportunity to obtain scintillation material with picosecond characteristics and intense luminescence signal. 


\section{Acknowledgements}

This work was supported by project ERANET RUS ST Nr. 2017-05 (Latvia) and Nr. 18-52-76002 (Russia).

Institute of Solid State Physics, University of Latvia as the Center of Excellence has received funding from the European Union's Horizon 2020 Framework Programme H2020-WIDESPREAD-01-2016-2017-TeamingPhase2 under grant agreement No. 739508, project CAMART ${ }^{2}$.

\section{AIP Publishing Data Sharing Policy}

The data that support the findings of this study are available from the corresponding author upon reasonable request.

\section{References}

[1] Özgür, Ü., Alivov, Y. I., Liu, C., Teke, A., Reshchikov, M. A., Doğan, S., et al. (2005) A comprehensive review of $\mathrm{ZnO}$ materials and devices. Journal of Applied Physics. 98 (4), 1103.

[2] Procházková, L., Gbur, T., Čuba, V., Jarý, V., and Nikl, M. (2015) Fabrication of highly efficient $\mathrm{ZnO}$ nanoscintillators. Optical Materials. 47 67-71.

[3] Moezzi, A., McDonagh, A. M., and Cortie, M. B. (2012) Zinc oxide particles: Synthesis, properties and applications. Chemical Engineering Journal. 185-186 1-22.

[4] Mishra, P. K., Mishra, H., Ekielski, A., Talegaonkar, S., and Vaidya, B. (2017) Zinc oxide nanoparticles: a promising nanomaterial for biomedical applications. Drug Discovery Today. 22 (12), 1825-1834.

[5] Sharma, D. K., Shukla, S., Sharma, K. K., and Kumar, V. (2020) Materials Today : Proceedings A review on $\mathrm{ZnO}$ : Fundamental properties and applications. Materials Today: Proceedings.

[6] Mičová, J., Buryi, M., Šimek, D., Drahokoupil, J., Neykova, N., Chang, Y. Y., et al. (2018) Synthesis of zinc oxide nanostructures and comparison of their crystal quality. Applied Surface Science. 461 190-195.

[7] Luckey, D. (1968) A fast inorganic scintillator. Nuclear Instruments and Methods. 62 (1), 119-120.

[8] Djuriić, A. B., Ng, A. M. C., and Chen, X. Y. (2010) ZnO nanostructures for optoelectronics: Material properties and device applications. Progress in Quantum Electronics. 34 (4), 191-259.

[9] Berezovska, N. I., Gubanov, V. O., Dmitruk, I. M., and Biliy, M M. (2003) Some peculiarities of exciton luminescence of zinc oxide single crystals and powders. Journal of Luminescence. 102-103 (SPEC), 434-437.

[10] Meyer, B. K., Alves, H., Hofmann, D. M., Kriegseis, W., Forster, D., Bertram, F., et al. (2004) Bound exciton and donor-acceptor pair recombinations in ZnO. Physica Status Solidi (B) Basic Research. 241 (2), 231-260.

[11] Lv, J., Li, C., and Chai, Z. (2019) Defect luminescence and its mediated physical properties in ZnO. Journal of Luminescence. $208225-237$.

[12] Neal, J. S., Giles, N. C., Yang, X., Wall, R. A., Ucer, K. B.,
Williams, R. T., et al. (2008) Evaluation of melt-grown, ZnO single crystals for use as alpha-particle detectors. IEEE Transactions on Nuclear Science. 55 (3), 1397-1403.

[13] Bourret-Courchesne, E. D., Derenzo, S. E., and Weber, M. J. (2009) Development of ZnO:Ga as an ultra-fast scintillator. Nuclear Instruments and Methods in Physics Research, Section A: Accelerators, Spectrometers, Detectors and Associated Equipment. 601 (3), 358-363.

[14] Charles Cooper, J., Koltick, D. S., Mihalczo, J. T., and Neal, J. S. (2003) Evaluation of $\mathrm{ZnO}(\mathrm{Ga})$ coatings as alpha particle transducers within a neutron generator. Nuclear Instruments and Methods in Physics Research, Section A: Accelerators, Spectrometers, Detectors and Associated Equipment. 505 (1-2), 498-501.

[15] Chernenko, K. A., Gorokhova, E. I., Eronko, S. B., Sandulenko, A. v., Venevtsev, I. D., Wieczorek, H., et al. (2018) Structural, Optical, and Luminescent Properties of $\mathrm{ZnO}: \mathrm{Ga}$ and $\mathrm{ZnO}: \mathrm{In}$ Ceramics. IEEE Transactions on Nuclear Science. 65 (8), 2196-2202.

[16] Rodny̆̌, P. A., Khodyuk, I. v., Gorokhova, E. I., Mikhrin, S. B., and Dorenbos, P. (2008) Emission and excitation spectra of $\mathrm{ZnO}: \mathrm{Ga}$ and $\mathrm{ZnO}: \mathrm{Ga}$, N ceramics. Optics and Spectroscopy (English Translation of Optika i Spektroskopiya). 105 (6), 908912.

[17] Derenzo, S. E., Weber, M. J., Bourret-Courchesne, E., and Klintenberg, M. K. (2003) The quest for the ideal inorganic scintillator. Nuclear Instruments and Methods in Physics Research, Section A: Accelerators, Spectrometers, Detectors and Associated Equipment. 505 (1-2), 111-117.

[18] Simpson, P. J., Tjossem, R., Hunt, A. W., Lynn, K. G., and Munné, V. (2003) Superfast timing performance from $\mathrm{ZnO}$ scintillators. Nuclear Instruments and Methods in Physics Research, Section A: Accelerators, Spectrometers, Detectors and Associated Equipment. 505 (1-2), 82-84.

[19] Ghanbari Shohany, B. and Khorsand Zak, A. (2020) Doped $\mathrm{ZnO}$ nanostructures with selected elements - Structural, morphology and optical properties: A review. Ceramics International. 46 (5), 5507-5520.

[20] Wilkinson, J., Ucer, K. B., and Williams, R. T. (2004) Picosecond excitonic luminescence in $\mathrm{ZnO}$ and other wide-gap semiconductors. Radiation Measurements. 38 (4-6), 501-505.

[21] Wilkinson, J., Ucer, K. B., and Williams, R. T. (2005) The oscillator strength of extended exciton states and possibility for very fast scintillators. Nuclear Instruments and Methods in Physics Research, Section A: Accelerators, Spectrometers, Detectors and Associated Equipment. 537 (1-2 SPEC. ISS.), 66-70.

[22] Xiong, G., Ucer, K. B., Williams, R. T., Lee, J., Bhattacharyya, D., Metson, J., et al. (2005) Donor-acceptor pair luminescence of nitrogen-implanted $\mathrm{ZnO}$ single crystal. Journal of Applied Physics. 97 (4).

[23] Li, Q., Liu, X., Gu, M., Huang, S., Zhang, J., Ni, C., et al. (2016) $\mathrm{X}$-ray excited luminescence of $\mathrm{Ga}$ - and In-doped $\mathrm{ZnO}$ microrods by annealing treatment. Superlattices and Microstructures. 98 351-358.

[24] Kano, M., Wakamiya, A., Sakai, K., Yamanoi, K., Cadatal-Raduban, M., Nakazato, T., et al. (2011) Response-time-improved $\mathrm{ZnO}$ scintillator by impurity doping. Journal of Crystal Growth. 318 (1), 788-790. 
[25] Grigorjeva, L., Grube, J., Bite, I., Zolotarjovs, A., Smits, K., Millers, D., et al. (2019) Sub-nanosecond excitonic luminescence in ZnO:In nanocrystals. Radiation Measurements. 123 (February), 69-73.

[26] Rodnyi, P. A., Mikhrin, S. B., Mishin, A. N., and Sidorenko, A. v. (2001) Small-size pulsed X-ray source for measurements of scintillator decay time constants. IEEE Transactions on Nuclear Science. 48 (6 II), 2340-2343.

[27] Demidenko, V. A., Gorokhova, E. I., Khodyuk, I. v., Khristich, O. A., Mikhrin, S. B., and Rodnyi, P. A. (2007) Scintillation properties of ceramics based on zinc oxide. Radiation Measurements. 42 (4-5), 549-552.

[28] Meyer, B. K., Sann, J., Hofmann, D. M., Neumann, C., and Zeuner, A. (2005) Shallow donors and acceptors in $\mathrm{ZnO}$. Semiconductor Science and Technology. 20 (4).

[29] Muktepavela, F., Maniks, J., Grigorjeva, L., Zabels, R., Rodnyi, P., and Gorokhova, E. (2018) Effect of in Doping on the ZnO Powders Morphology and Microstructure Evolution of ZnO:In Ceramics as a Material for Scintillators. Latvian Journal of Physics and Technical Sciences. 55 (6), 35-42.

[30] Lu, K. (2008) Sintering of nanoceramics. International Materials Reviews. 53 (1), 21-38.

[31] Vorobyeva, N., Rumyantseva, M., Filatova, D., Konstantinova, E., Grishina, D., Abakumov, A., et al. (2013) Nanocrystalline $\mathrm{ZnO}(\mathrm{Ga})$ : Paramagnetic centers, surface acidity and gas sensor properties. Sensors and Actuators, B: Chemical. 182 (2013), 555-564.

[32] Cuscó, R., Alarcón-Lladó, E., Ibáñez, J., Artús, L., Jiménez, J., Wang, B., et al. (2007) Temperature dependence of Raman scattering in ZnO. Physical Review B - Condensed Matter and Materials Physics. 75 (16), 1-11.

[33] Demangeot, F., Paillard, V., Chassaing, P. M., Pagès, C., Kahn, M. L., Maisonnat, A., et al. (2006) Experimental study of LO phonons and excitons in $\mathrm{ZnO}$ nanoparticles produced by room-temperature organometallic synthesis. Applied Physics Letters. 88 (7), 2-5.

[34] Das, D. and Mondal, P. (2016) Low temperature grown $\mathrm{ZnO}: \mathrm{Ga}$ films with predominant c-axis orientation in wurtzite structure demonstrating high conductance, transmittance and photoluminescence. RSC Advances. 6 (8), 6144-6153.

[35] Mondal, P. and Das, D. (2016) Effect of hydrogen in controlling the structural orientation of $\mathrm{ZnO}: \mathrm{Ga}: \mathrm{H}$ as transparent conducting oxide films suitable for applications in stacked layer devices. Physical Chemistry Chemical Physics. 18 (30), 20450-20458.

[36] Makino, T., Segawa, Y., Yoshida, S., Tsukazaki, A., Ohtomo, A., and Kawasaki, M. (2004) Gallium concentration dependence of room-temperature near-band-edge luminescence in n-type $\mathrm{ZnO}: \mathrm{Ga}$. Applied Physics Letters. 85 (5), 759-761. 